\title{
1986-1991 DÖNEMI TÜRKIYE GREVLERININ BIR ANALIZI: HAZARD MODELI YAKLAŞIMI
}

\author{
Dr. Hasan Şahin'1 \\ Ankara Üniversitesi \\ Siyasal Bilgiler Fakültesi
}

\section{Özet}

Bu ampirik çalışma 1986-1991 yılları arasındaki Türkiye'deki grevlerin bir analizini yapmaktadır. Analizde ekonomik çalışmalarda yeni bir yaklaşım olarak kabul edilen hazard modeli yaklaşım kullanılmıştır. Çalışma grev süresi ile greve katılan iş̧̧i sayısı arasında negatif bir ilişki bulmuştur. llgili dönemde ortaya çıkan grevler greve katılan iş̧̧i sayısına göre küçük orta ve büyük grevler olarak alt kategorilere ayrilmuş ve bu grevlerin üstel hazard fonksiyonu ile temsil edilebileceği sonucuna varılmuştır. Bu sonuç devam etmekte olan bir grevin sona erme olasılığının grevin kaç gün sürdüğünden bağımsız olduğuna ifade etmektedir. Bununla birlikte küçük grevlerin ortalama olarak büyük grevlerden iki kat daha uzun sürdüğü sonucuna varılmıştır.

\section{An Analysis of Turkish Strikes During 1986-1991: A Hazard Model Approach}

\section{Abstract}

This empirical study analyzes the strikes occurred during the period of 1986-1991. The hazard model approach, a relatively new approach in econometrics, is used in this study. The study finds a significant relationship between the length of strikes and the number of workers at the outset of the strikes. Strikes are divided into three categories, namely small, medium, and large strikes, based on the number of workers involved. The exponential hazard fits best for all three types of strikes. This result shows that the process of strikes is memoryless. The implication of an exponential hazard is that probability of a strike ends in a short time, given that the strike still continues is the same for strikes that have different lengths. The study also finds that the mean duration of large strikes are expected to be as much as two times higher than that of small strikes. Some policy implications of the results are also discussed.

1 Makalenin daha anlaşılabilir hale gelmesi konusundaki önerilerinden dolayı hakeme teşekkür ederim. Bununla birlikte makaledeki eksik ve hatalar yazara aittir. 


\section{6-1991 Dönemi Türkiye Grevlerinin Bir Analizi: Hazard Modeli Yaklaşımı}

\section{Giriş}

Bu çalışmada 1986 yılından 1991 yılına kadar Türkiye'de ortaya çkan grevlerin bir analizi yapılmaktadır. Bu amaçla ekonometrik literatürde kullanımı son yıllarda uygulama alanı bulan hazard modeli ${ }^{2}$ yaklaşımı seçilmiştir. Bu çalışmada greve katılan iş̧i sayısının grev süresi üzerindeki etkisi test edilecek ve büyük ve küçük ölçekli şirketlerin grev sürelerinin farklılı̆̆ çözümlenecektir. Türkiye'deki grevlerin tanımsal analizine ilişkin genel olarak sendikaların yayınları bulunmakla beraber bu grevlerin nicel bir analizine rastlanmamıştır. Bu anlamda çalışmanun katkısı Türkiye'deki grevlerin ilk defa nicel analizini yapmasıdir.

Hazard modelleri iki olay arasında geçen zaman (duration) analiz etmek amacıyla geliştirilmiş ve uygulama alan genel olarak mühendislik ve tıp olmakla birlikte son yıllarda ekonomi alanunda da kullanılmaya başlanmıştır. Modelin potansiyel ve mevcut uygulama alanları iki doğum arasındaki zaman, doktora derecesine alana kadar geçen zaman, savaşlann uzunluğu, seçimle işbaşı yapanların görevlerinin uzunluğu, firmaların faaliyet süreleri, evliliğin süresi olarak gösterilebilir.(KIEFER, 1988:648)

Hazard modeli yaklaşımı bir olayın başlayışından bitişine kadar geçen sürenin modellenmesinde tercih edilmektedir. Bu yaklaşım dinamik analizi içerisinde barındırmaktadır. Ekonometrik çalışmalarda klasik yöntem olarak da adlandınlabileceğimiz yaklaşım verilerin düzenli aralıklarla toplanarak analiz edilmesidir. Bu zımni olarak ekonomik karar birimlerinin düzenli aralıklarla kararlarının oluşturduğunu varsaymaktadır. Oysa hazard modellerinde böyle bir durum söz konusu değildir. Aksine hazard modelleri karar vericilerin her an kararlarını oluşturabileceğini dikkate alan bir dinamik modeflemedir.

2 Hazard modellerine ayn zamanda duration (süre), failure time ve reliability modelleri adı da verilmektedir. 
Grev, iş̧̧i ve işveren arasındaki pazarlık sürecinin ${ }^{3}$ işç lehine sonuçlanmamasıyla

üretimin durdurulması şeklinde kendini gösteren bir eylemdir (LANCASTER, 1972: 257). Bu genel tanımı yasalarımız hukuki olarak daha kapsamlı bir şekilde düzenlemiştir. 5/5/1983 tarihinde kabul edilip 7/5/1983 tarih ve 18040 sayılı resmi gazete yayılanarak yürürlüğe giren 2822 sayılı Toplu iş sözleşmesi, grev ve lokavt kanununun 25. Maddesi grevi şu şekilde tanumlamaktadir:

"Iş̧ilerin, topluca çalışmamak suretiyle işyerinde faaliyeti durdurmak veya işin niteliğine göre önemli ölçüde aksatmak amacıyla aralarında anlaşarak veyahut bir kuruluşun aynı amaçla topluca çalışmamaları için verdiği karara uyarak işi bırakmalarına grev denilir."

Aynı kanun maddesi yasal ve yasal olmayan grev ayrımını yapmıs ve hangi durumlara yönelik grev yaplamayacağın belirtmiştir. Grev sonuçları itibariyle hem iş̧̧iyi hem de işvereni hem de grevin boyutuna ve bulunduğu sektöre bağlı olarak tüm tüketicileri etkileyen bir eylemdir. Bu nedenle grevlerin kısa süreli olması bütün kesimlerce arzu edilen bir durumdur. Grev sürelerinin ortalama ne kadar sürdüğü ve bu süreyi nelerin etkilediğinin tespiti önemlidir.

Grevlerin ortaya çıkışlarına ilişkin alternatifler görüşler mevcuttur. Ashenfelter ve Johnson'in (1969) modeli grevi pazarlık sürecine katılan sendika ile işçilerin amaçlarının farklılı̆̆ından ziyade sendika üyeleri ile sendika liderlerinin amaçlarının farklılığından kaynaklandığın ileri sürmektedir. Sendika liderleri sadece iş̧̧lerinin kazanumları ile değil aynı zamanda sendikanın büyümesi ve yaşaması ile ve kendi kişisel amaçları ile de ilgilenmektedir. Bu amaç çeşitliliği sendika liderlerini istemedikleri halde greve gitme kararın almak zorunda bırakabilmektedir. Bu modelde sendika liderlerinin işverenin finansal gücü hakkında sendika üyelerinden daha fazla bilgiye sahip olduğu, üyelerin istemiş olduğu iyileştirmenin mümkün olmadığın bilmesine karşın üyeleri ikna edemediğinden kendi konumunu koruyabilmek için greve gidebildiği sonucuna varılmaktadır.

Ashenfelter ve Jonhson'dan sonra grev faaliyetlerini açılamaya yönelik yeni modeller önerilmiştir. Asimetrik bilgi modeli (HAYES, 1984), toplam maliyet (total cost) modeli (REDER / NEUMAN, 1980) bunlara örnek modelleme çabalarıdır. Bu modellerin ortak özelliği sendika üyelerinin Ashenfelter ve Johnson'in modelinde varsayıldığı gibi grev kararlının alınmasında pasif olmadıklandır. Üyeler grev kararlarının alınmasında aktif bir

$3 \mathrm{Bu}$ pazariık sürecindeki asıl konu ücretlerin artırılması olmakla birlikte iş̧ilerin diğer özlük haklanna ilişkin düzenlemelerde pazarlık sürecinin ve grevin nedeni olabilmektedir. Örneğin çalışma saat ve koşullarının düzenlemesi grev nedeni olarak ortaya çlkabilmektedir. 
rol oynamaktadır. Yakın zamanlarda geliştirilen modeller daha çok yukarıdaki modellerin bir versiyonu olarak karşımıza çıkmaktadır. Örneğin Fisher (2001) asimetrik modelin bir başka versiyonudur. Modelde firma pazarlık gücüne sendika ise özel (private) bilgiye sahiptir. Fisher (2001) firmanın lokavt hakkın sendikanun sahip olduğu bilgiyi ortaya ģkarmak amaciyla kullanabileneceğini ve böylelikle greve gitmeden pazarlı̆ın sonuçlanabileceğini söylemektedir.

Çalışma şu düzen içinde kendini göstermektedir Ikinci bölümde çalışmada kullanılan veri ve hazard modeli hakkında bilgi verilmektedir. Üçüncü bölüm modelin tahmin sonuçlarını değerlendirmekte ve sonuç bölümüyle çalışma sona ermektedir.

\section{Model ve Veri}

\section{Veri}

Çalışmada 1986-1991 yıllarında Türkiye'de ortaya çıkan grevlere ait veri kullanılmıştır. Bu çalışmada kullanılan veri Türkiye Petrol Kimya, Lastik iş̧̧ileri Sendikası'nın yayınlamış olduğu yıllıklardan derlenmiştir. Incelenen dönem 1986 ylı ile 1991 yılının ilk altı ayıdır. Grev süresi gün olarak ifade edilmektedir. En kusa grev 0 (sıfır) gün en uzun grev ise 859 gün sürmüştür. Tablo 1'de görüldüğü üzere bu zaman kesitinde toplam 511 grev bulunmaktadır. Bu grevlerin hepsi inceleme dönemi itibariyle bitmemiştir. Grevlerin 26 tanesi devam etmektedir. Öte yandan Bakanlar Kurulu grevleri erteleme yetkisini kullanarak toplam 207 grevi ertelemiştir. Erteleme olayı grev sürecinin kesintiye uğratılması olup bu hususu da kapsayacak şekilde modeli düzenleyebilmek mümkün olabilmekle birlikte burada hükümet kararları ile etkilenlenmemiş grevleri incelemck istediğimizden ertelenen grevler örneklemden çıkarılmıştır. Erteleme olayı grevin söz konusu olduğu işyeri büyüklügünden bağımsız olduğundan ertelenen grevler seçme sapması (selection bias) problemi yaratmayacaktır. Bu düzenlemeler sonucu çalışmaya ilişkin veri setimiz 304 greve sahiptir.

Tablo 1. Grevlerin dağlumı (1986-1991 (ilk altı ay))

\begin{tabular}{|l|c|c|}
\hline Statüsü & Say1 & Yüzde \\
\hline Devam ediyor & 26 & 5.09 \\
\hline Bitti & 278 & 54.40 \\
\hline Ertelendi & 207 & 40.51 \\
\hline Toplam & 511 & 100.00 \\
\hline
\end{tabular}

Kaynak : Türkiye Petrol Kimya, Lastik iş̧̧ileri Sendikasının ilgili yıllara ilişkin ylllkklanndan derlenmiştir. 


\section{Hazard Modelleri}

Hazard modelleri girişte de belirtildiği üzere iki olay arasında geçen zaman modellemek amaciyla kullanılmaktadır. Süre (duration) iki olay veya bulunulan konumun değişimi (change of state) arasında geçen zaman olarak tanımlanabilir. Olayın başlangıç zamanı ve zaman türü (gün hafta ay vb) sürenin hesaplanması için açk bir şekilde tanımlanmalıdır (FLORENS vd. 1996: 492). Değişimin olduğu nokta başarısızlık (failure) veya çıkış (exit) noktası olarak adlandırılır. Örneğin grevin sona ermesi başarısızlık noktası ve grev bitinceye kadar geçen zamanda süredir (duration).

Kümülatif olasılık veya olasilı sıklık fonksiyonları süre verileri modellenmesinde kullanilmakla beraber hazard fonksiyonu da kullanilmaktadır. Olasılık fonksiyonu anlık başarısızlık olasılı̆ııu buna karsın hazard fonksiyonun anlık şartlı başarısızlık olasılığını verir. Hazard fonksiyonu tanımlaması birden fazla çıkıs olduğunda veya veriler sansüre (cencored) ${ }^{4}$ uğradığında sağladığı kolaylıktan dolayı tercih edilmektedir (COX /OAKES 1984: 16). Tesadüfi değişken $T$ belli bir durumda (state) (örneğin grevde işsizlikte) geçen süreyi gösteren devamlı bir değişken olarak tanımlansın ${ }^{5}$. Sürenin olasılık dağılımı kümülatif dağlım fonksiyonu ile belirlenebilir,

Tablo 2. Tesadüfi bir değişkenin fonksiyonlan

\begin{tabular}{|l|l|}
\hline Kümülatıf Olasilik Fonksiyonu (cdf) & $F(t)=P(T<t)=\int_{0}^{t} f(s) d s$ \\
\hline Olasılık Siklık Fonksiyonu (pdf) & $(t)=d F(t) / d t$ \\
\hline Survivor Fonksiyonu & $S(t)=P(T>t)$ \\
\hline Hazard Fonksiyonu & $\lambda(t)=\operatorname{Lim}_{d t \rightarrow 0} \frac{P(t \leq T<+d t \quad \mid T \geq t)}{d t}$ \\
& $\lambda(t)=\frac{f(t)}{S(t)}$ \\
\hline
\end{tabular}

4 Veri cencored olduğunda belirle bir aralık içindeki değerler tek bir değer olarak rapor edilir. Örneğin dayanklı tr̈ketim malları için yapılan harcamalar belirli bir düzeyin altında olduğunda sıfır olarak gösterilir (KENNEDY, 1998:251).

5 Değişkenin kesikli olarak tanımlanması da mümkündür. Bu durumda tanımlarımıdaki integral işaretini summation (toplama) işaretine çevirmemiz gerekir.(KALBFLEISCH /PRENTICE, 1980:7). 
$F(t)=P(T<t)=\int_{0}^{t} f(s) d s$ Kümülatif dağılım fonksiyonu tesadüfı değişken $T$ 'nin t'den küçük olma olasılığın verir. Buna karşılık gelen sıklık fonksiyonu $f(t)=d F(t) / d t$ 'dir. Kümülatif dağılım ile sıklık fonksiyonu aym dağılımı ifade ettiğinden hangisinin kullanulacağının seçimi bu fonksiyonların analizde sağlayacağı kolaylığa bağlıdır. Bir diğer fonksiyon ise survivor fonksiyonudur,

$$
S(t)=1-F(t)=P(T \geq t)
$$

bu fonksiyon tesadüfi değiş̧en T'nin t'ye eşit yada daha büyük olma olasılığın verir. Survivor fonksiyonunu tanumlamak T'nin dağllımını belirlemenin diğer bir yoludur. Eğer herhangi bir durumun (örneğin grevin) ne kadar süreceği ana çalışma konusu ise kümülatif dağılım fonksiyonu yada sıklık fonksiyonu tanumlanabilir Bununla birlikte eğer bu durumun $t$ kadar bir süre sürmesi (örneğin 45 gün sürmesi) koşulu ile kısa bir zaman aralığında (örneğin bir gün içinde) bu durumun sona erme olasılığı daha önemli ise o zaman hazard fonksiyonunu tanumlamak daha uygun bir yaklaşım olacaktır. Bir olayın en az t kadar sürmesi şartıyla kısa bir dt zaman aralığında sona ermesi olasılığı ifadesi matematiksel olarak $P(t \leq T<t+d t \mid T \geq t)$ şeklinde yazllabilir. Bu son ifade bize T'nin şartlı dağılımını verirken sıklık ve kümülatif dağılım fonksiyonları şartsız dağılımını vermektedir. Eğer bu şartlı dağılımı dt ile böler ve dt'yi küçültürsek hazard fonksiyonun taniminı elde ederiz (LANCASTER, 1990: 7).

$$
\lambda(t)=\operatorname{Lim}_{d t \rightarrow 0} \frac{P(t \leq T<+d t \mid T \geq t)}{d t}
$$

Yukarıda ifade bize anlık durum (state) değiştirme olaslığın verir. Bu tanumlamada ilgilenilen konu sadece bulunulan konumdan anlik ayrilma olasılı̆̆ıdır oysa ekonomik analizlerde çoğu zaman bağımsız değişkenlerin ${ }^{6}$ anlık ayrilma olasılı̆ı üzerindeki etkisiyle ilgilenilmektedir. Bu durumda hazard fonksiyonu aşağıdaki gibi yazılır

$\lambda(t, x)=\lim _{d t \rightarrow 0} \frac{P(t \leq T<t+d t \mid T \geq t, x)}{d t} \quad \underline{x}$ bağımsız değişkenleri içeren vektör-

dür. Hazard fonksiyonu şartsız (unconditional) dağılımlarla da ifade edilebilir, hazard fonksiyonu sıklık fonksiyonunun survivor fonksiyonuna orandır.

$$
\lambda(t)=\frac{f(t)}{S(t)}
$$

6 Bağımsız değiskenler kavramı independent variables'e karşılık gelmektedir. Duration çalışmalarında independent variables covariates olarak adlanmaktadır. 
Bütün bu fonksiyonlar (kümülatif dağlım, sıklık, survivor ve hazard fonksiyonları) biribirileri ile ilişkilidir ve bu fonksiyonlardan birini bilmek diğerlerini çıkarmaya yeterlidir. Tablo 2 bu ilişkiyi göstermektedir (GREENE, 1997: 986-996).

Eğer hazard fonksiyonun birinci derece türevi, $d \lambda(t) / d t, t=t^{*}$ değerinde pozitifse, hazard fonksiyonun $t^{*}$ da pozitif duration bağımlılığa sahip olduğu söylenir. Pozitif duration bağımlllı̆̆ bir konumdan (state) ayrılma olasılığının sürenin uzunluğu arttıkça arttığı anlamina gelir. Benzer şekilde $d \lambda(t) / d t$, 'nin eksi değeri negatif duration bağımllığını ifade eder. Üstel (Exponential) dağılım duration bağımlllı̆ı göstermez. Weibull dağılımı parametrelerin değerine göre non monotonik pozitif yada negatif duration bağımlılı̆̆ gösterir (KIEFER, 1988:652).

Ampirik analist hazard fonksiyonuyla çalş̧mayı sıklık fonksiyonu ile çalışmayı yeğleyebilir. Bunun bir nedeni ekonomik teorinin hazard fonksiyonun alacağ 1 formu vermesindendir ( Heckman ve Singer, 1980: 272). Hesaplama zorluklarn ve başka hususlar analisti ekonomik teorinin önermediği bir fonksiyonel formu hazard fonksiyonu olarak tercih etmeye zorlayabilir. Ekonometrik çalışmalarda genellikle ilk tercih olan normal dağılım hazard çalışmalarında negatif durationa imkan verdiğinden kullanılmamaktadır. Hazard analizlerinde sıkça kullanulan fonksiyonlar üstel, Weibull, lognormal, F, gamma, ters (inverse) normal, Gompertzdir.

Hazard modelleri genel olarak tanımlandıkları dağılımın adını alır üstel (exponential) ve Weibull hazard modelleri gibi. Örneğin Weibull hazard modeli monotonik duration bağımlılı̆̆ı gösterir ve aşağıdaki formda ifade edilebilir.

$$
\lambda\left(t_{i}\right)=\alpha p(\alpha t)^{p-1}
$$

$\mathrm{p}=1$ olduğunda hazard fonksiyonu üstel hazard fonksiyonu ismini alır. Üstel hazard fonksiyonu memoryless özelliğini taşır. Bunun anlamı devam etmekte olan bir grev ile yeni başlayan bir grevin sona erme olasılığınun ayn olmasıdır. Weibull olasılık sıklık, hazard ve survivor fonksiyonları sırasıyla, $\alpha p(\alpha t)^{p-1} e^{-(\alpha t)^{p}}, \alpha p(\alpha t)^{p-1}, e^{-(\alpha t)^{p}}$. p parametresinin $1^{i} \mathrm{e}$ eşit olması halinde surasıyla üstel fonksiyonun sıklık, hazard ve survivor fonksiyonların elde etmiş oluruz (KALBFLEISCH/PRENTICE, 1980:22-24).

Duration modellerinin tahmin edilmesinde olasilık fonksiyonu belirlendiğinden genellikle maksimum olabilirlik yöntemi kullanılmaktadır. Cencored veri olmadığında her bir gözlemin olabilirlik fonksiyonuna katkısı sıklık fonksiyonu olacaktır. Ancak cencored edilmiş veri hakkında tek bilenen grevin hala devam ettiğidir. Bu yüzden cencored edilmiş verinin katkısı survivor fonksiyonudur. Bu bilgiler doğrultusunda maksimize edilecek log likelihood fonksiyonu genel olarak aşağıdaki gibi yazılabilir. 


$$
\log L=\sum_{u} \ln f(t)+\sum_{c} \ln F(t)
$$

u ve c sirasiyla cencor edilmemiş ve edilmiş verileri ifade eder. Bununla birlikte eğer verilerin homojen bir gruptan geldiği kabul edilirse Kaplan- Meier tahmin edicisi veya Cutler-Ederer yöntemi kullanularak ampirik olarak hazard ve survivor fonksiyonu elde edilebilir. Her iki yöntem censored veri olmadığında aynı şekilde hesaplanur. Yöntemlerin farklılığı kendini censored veri durumunda ve ayn değere sahip birden fazla duration olduğunda gösterir ${ }^{7}$. Cencored veri ve ayn değere sahip süre olmadığında survivor fonksiyonu ve hazard fonksiyonu şu şckilde hesaplanır:

Önce bütün gözlemler küçükten büyüğe doğru sıralanur. $h_{j}, t_{j}$, süresine sahip cencora uğramamıs gözlem sayısın $m_{j}, t_{j}$ ve $t_{j+1}$ arasında cencora uğramıs gözlem sayısını ve $n_{j}$ süre $t_{j}$ 'den önce tamamlanmayan ve cencora uğramayan gözlem sayısı göstersin, $n_{j}=\sum_{i \leq j}^{K}\left(m_{i}+h_{i}\right)$. Bu tanımlamalar altında hazard ve survivor fonksiyonunu Kaplan Meier tahmi edicileri sırasıyla, $\hat{\lambda}=h_{j} / n_{j}$, $\widehat{S}=\prod_{i=1}^{j}(1-\widehat{\lambda})$ 'dır (KIEFER, 1988: 659).

Grev süresini etkileyebilecek değişkenlerin modele sokulması mümkün olmakla beraber bu çalı̧̧mada böyle bir yol seçilmemiştir. Bunun nedeni herhangi bir açıklayıd değişkene bağlı kalmadan grevlerin modellenmesinin mümkün olup olmadığın araştırmaktır. Bu çalışmanın bir uzantısı grev süresini etkileyebileceği düşünülen zamana bağlı (time-varying) ve zamana bağlı olmayan değişkenlerin hazard fonksiyonuna sokularak grev süresini ne yönde değiştireceğini araştırmak olabilir.

\section{Model tahmini ve ampirik sonuçlar}

Bütün tahminlerde LIMDEP V.7 paket programı kullanlmıştır 8 . Öncelikle grevlerin homojen 9 olduğu varsayımı ile herhangi bir fonksiyonel varsayım kullanmadan non parametrik yöntemle elde edilen Tablo 3 'de yer alan yaşam tablosu (life table) elde edilmiştir. Yaşam tablosu ampirik survivor ve hazard fonksiyonların tahmin etmeye yarar. Survivor fonksiyonu grevin belirtilen süreden daha uzun olma olasılığın vermektedir. Örneğin 30.7 ile 61.7

7 Bu yöntemler ve diğer parametrik olmayan yöntemler için bakınız (COX/O^KES, 1984).

8 Grafikler Matlab programı ile çizilmiştir.

9 Homojenlik grevlerin herbirisinin aynı olasılık fonksiyonuna sahip olduğunu ifade etmektedir. 
gün arasındaki bir grevin daha uzun devam etmesi olasıllğı yaklaşık \% 74'tür. Ampirik hazard fonksiyonu ise halen sürmekte olan bir grevin sona erme olasılığını verir. Tabloya baktığımızda 30.7-61.7 aralığına düşen devam etmekte olan bir grevin sona erme olasılı̆̆ının \% 0.90 olduğunu görürüz. Bu tablodan görüleceği üzere genel eğilim süre arttıkça hazard oranının artmasıdır. Bu beklentilere uygundur; ampirik hazard fonksiyonu grev süresi uzadıkça grevin kısa süre içinde sona erme olasılığının arttığın söylemektedir.

Grev süresi ile greve katılan işçi sayısı arasında regresyon neticesi grevin uzunluğu ile greve katılan iş̧̧ sayısı arasında negatif bir ilişki olduğunu göstermiştir (Ek Tablo 1). Ilişkinin rakamsal büyüklüğü Lancaster'in (1972) değerlerine yakındır. Bununla birlikte elde edilen regresyon sonucu sadece yol gösterici olarak kabul edilmelidir. Zira grevlerin bazıları sansüre uğramış olduğunda en küçük kareler yöntemi ile elde edilen tahmin ediciler standart metoda göre test edilemezler.

Greve katılan iş̧ilerin sayısının grev üzerindeki etkisini daha detaylı irdelemek için katılan iş̧̧ sayısına göre grevler küçük orta ve büyük çaplı grevler olmak üzere üç kategoriye ayrılmıştır. Bir -yüz işçinin katıldığı grevlere küçük grevler yüz bir - beş yüz iş̧̧inin katıldığı grevler orta grevler ve beş yüz birden fazla iş̧inin katıldı̆̆ grevler büyük grev olarak tanımlanmıştır.

$\mathrm{Bu}$ grevlerin süresel olarak aynı özelliği sahip olup olmadıklanna ilişkin test neticesinde üç ayrı kategorinin farklı özelliklere sahip olduğu sonucuna varimıştır. Bu amaçla Log-Rank (LM) ve generalized Wilcoxon ${ }^{10}$ testi uygulanmıştır. Her iki test sonucu grevlerin aynı yapıda oldukları hipotezi \% 1 anlamlllık düzeyinde bile kabul edilememiştir. Sonuçlar Ek Tablo 2 de yer almaktadir.

Homojen bir yapıya sahip olmadığ tespit edilen bu grevlerin hangi fonksiyonel yapıya daha uygun olduğunu tespit etmek için üstel, Weibull, normal, logistic, genelleştirilmiş gamma fonksiyonları ve maksimum olabilirlik yöntemi kullanılarak parametre tahmini yapılmıştır. Yer tasarrufu açısından sadece üstel ve Weibull fonksiyonlarına ait sonuçlar burada sunulmuştur ${ }^{11}$. Tablo 4'te görüldüğü üzere üstel ve Weibull fonksiyonları küçük orta ve büyük çaplı grevlere ve bütün grevlere uygulanmıştır. Ek Grafik 1'de Weibull fonksiyonunun tahmin edilen hazard fonksiyonu verilmiştir. Üstel fonksiyonun hazard fonksiyonu yatay eksene paralel bir doğru olduğundan bu fonksiyonun grafiğine yer verilmemiştir. Weibull hazard fonksiyonu büyük ve orta boy

$10 \mathrm{LM}$ testi genel olarak güçlü olmakla birlikte cencored veri olduğunda testlerin etkinlik (efficiency) özellikleri genellikle bilinmediğinden (KALBFLEISCH/PLENTICE, 1980:159) her iki test sonucuda verilmiştir.

$11 \mathrm{Bu}$ fonksiyonlara ilişkin sonuçlar yazardan talep edilebilir. 
grevlerin hazard oranının zamanla arthğını göstermektedir. Bu beklentilere uygun sonuç Tablo 4 'te orta boy ve büyük boy grevlerine ait $\mathrm{P}$ katsayısının 1'e eşit olduğu hipotezi reddedilemediğinden istatistiksel olarak anlamlı değildir.

Tablo 3. Ampirik Survivor fonksiyonu ve hazard oran

\begin{tabular}{|c|c|c|c|c|c|c|}
\hline Survival & Giren & Cencored & Riskteki & Biten & Surv. Oranı & Hazard Oranı \\
\hline $0.0-30.7$ & 304 & 8 & 300 & 77 & $1.0000(0.000)$ & $0.0096(0.001)$ \\
\hline $30.7-61.4$ & 219 & 8 & 215 & 52 & $0.7433(0.025)$ & $0.0090(0.001)$ \\
\hline $61.4-92.0$ & 159 & 7 & 155 & 72 & $0.5636(0.029)$ & $0.0196(0.002)$ \\
\hline $92.0-122.7$ & 80 & 0 & 80 & 24 & $0.3026(0.027)$ & $0.0115(0.002)$ \\
\hline $122.7-153.4$ & 56 & 1 & 55 & 12 & $0.2118(0.025)$ & $0.0079(0.002)$ \\
\hline $153.4-184.1$ & 43 & 0 & 43 & 8 & $0.1660(0.023)$ & $0.0067(0.002)$ \\
\hline 184.1- 214.8 & 35 & 0 & 35 & 5 & $0.1351(0.021)$ & $0.0050(0.002)$ \\
\hline $214.8-245.4$ & 30 & 2 & 29 & 1 & $0.1158(0.020)$ & $0.0011(0.001)$ \\
\hline $245.4-276.1$ & 27 & 0 & 27 & 3 & $0.1118(0.019)$ & $0.0038(0.002)$ \\
\hline $276.1-306.8$ & 24 & 0 & 24 & 3 & $0.0994(0.018)$ & $0.0043(0.003)$ \\
\hline $306.8-337.5$ & 21 & 0 & 21 & 2 & $0.0870(0.017)$ & $0.0033(0.002)$ \\
\hline $337.5-368.1$ & 19 & 0 & 19 & 8 & $0.0787(0.017)$ & $0.0174(0.006)$ \\
\hline $368.1-398.8$ & 11 & 0 & 11 & 5 & $0.0456(0.013)$ & $0.0192(0.008)$ \\
\hline $398.8-429.5$ & 6 & 0 & 6 & 1 & $0.0249(0.010)$ & $0.0059(0.006)$ \\
\hline $429.5-460.2$ & 5 & 0 & 5 & 2 & $0.0207(0.009)$ & $0.0163(0.011)$ \\
\hline $460.2-490.9$ & 3 & 0 & 3 & 0 & $0.0124(0.007)$ & $0.0000(0.000)$ \\
\hline $490.9-521.5$ & 3 & 0 & 3 & 1 & $0.0124(0.007)$ & $0.0130(0.013)$ \\
\hline $521.5-552.2$ & 2 & 0 & 2 & 1 & $0.0083(0.006)$ & $0.0217(0.020)$ \\
\hline $552.2-582.9$ & 1 & 0 & 1 & 0 & $0.0041(0.004)$ & $0.0000(0.000)$ \\
\hline $582.9-613.6$ & 1 & 0 & 1 & 0 & $0.0041(0.004)$ & $0.0000(0.000)$ \\
\hline $613.6-644.3$ & 1 & 0 & 1 & 0 & $0.0041(0.004)$ & $0.0000(0.000)$ \\
\hline $644.3-674.9$ & 1 & 0 & 1 & 0 & $0.0041(0.004)$ & $0.0000(0.000)$ \\
\hline $674.9-705.6$ & 1 & 0 & 1 & 0 & $0.0041(0.004)$ & $0.0000(0.000)$ \\
\hline $705.6-736.3$ & 1 & 0 & 1 & 0 & $0.0041(0.004)$ & $0.0000(0.000)$ \\
\hline 736.3- 767.0 & 1 & 0 & 1 & 0 & $0.0041(0.004)$ & $0.0000(0.000)$ \\
\hline $767.0-797.6$ & 1 & 0 & 1 & 0 & $0.0041(0.004)$ & $0.0000(0.000)$ \\
\hline $797.6-828.3$ & 1 & 0 & 1 & 0 & $0.0041(0.004)$ & $0.0000(0.000)$ \\
\hline 828.3- 859.0 & 1 & 0 & 1 & 1 & $0.0041(0.004)$ & $0.0652(0.000)$ \\
\hline
\end{tabular}


Tahmin sonuçlarınun incelenmesi neticesinde Tablo 4 'te oluşan ortak nokta Türkiye'deki grevlere üstel fonksiyonun daha uygun olmasıdır. Bütün durumlarda Weibull parametresinin 1'e eşit olduğu hipotezi reddedilememektedir. Bu söz konusu dönemdeki grevlerin üstel bir fonksiyonla ve dolayısıyla sabit bir hazard oranu ile açıklanabileceğini göstermektedir. Bu yeni başlayan bir grevle öteden beri devam etmekte olan bir grevin sona erme olasılığının ayn olduğu sonucuna bizi götürmektedir. Sonuç şaşırtıcı gözükmektedir. Beklentilere uyan grevin sona erme olasılığınun belirli bir süreye kadar pozitif yönde hareket etmesi ve bir uç değere ulaştıktan sonra ise azalmasıdır.

Hazard modellerinde uyumun iyiliğinin (goodness of fit) değerlendirilmesinin bir yolu grafiksel yöntemdir. Bu yöntemde integrated hazardın süreye karşı çizilen grafiğin eğimin 45 derece açıya yakınlığı söz konusu fonksiyonel formun uygunluğu gösterir. Bu amaçla üstel ve Weibull fonksiyonlarının integrated hazard fonksiyonları Ek Grafik 2'de verilmiştir. Genel değerlendirme üstel fonksiyonun verileri daha iyi temsil ettiği sonucuna bizi ulaştırmaktadır

Grupların ayrı ayrı incelenmesi her bir gruptaki hazard oranının ve buna bağh olarak model tarafından tahmin edilen ortalama grev uzunluğunun oldukça farklı olduğunu göstermektedir. Örneğin küçük grevler için ortalama uzunluk 125 gün iken bu süre büyük grevler için 59 güne düşmektedir. Fazla iş̧̧ katılımı grevin ortalama süresini yarı yanya düşürmektedir. Greve katılım fazla olduğu taktirde grevin kısa sürede sonuçlanma olasılığı artmaktadır. 
Tablo 3. Üstel (Exponential) ve Weibull modellerinin tahmin sonuçlan

\begin{tabular}{|c|c|c|c|c|c|c|c|c|}
\hline & \multicolumn{2}{|c|}{ Küçük Grevler } & \multicolumn{2}{|c|}{ Orta Grevler } & \multicolumn{2}{|c|}{ Büyük Grevler } & \multicolumn{2}{|c|}{ Hepsi } \\
\hline , & Üstel & Weibull & Üstel & Weibull & Üstel & Weibull & Üstel & Weibull \\
\hline$\alpha$ & $\begin{array}{c}0.00796^{*} \\
(0.00066)\end{array}$ & $\begin{array}{c}0.00815^{*} \\
(0.00082)\end{array}$ & $\begin{array}{l}0.01086^{*} \\
(0.00099)\end{array}$ & $\begin{array}{c}0.01077^{*} \\
(0.00107)\end{array}$ & $\begin{array}{c}0.01689^{*} \\
(0.00238)\end{array}$ & $\begin{array}{c}0.01632^{*} \\
(0.00216)\end{array}$ & $\begin{array}{c}0.00998^{*} \\
(0.00053)\end{array}$ & $\begin{array}{c}0.0104^{*} \\
(0.00067)\end{array}$ \\
\hline$P$ & - & $\begin{array}{l}0.94199^{* *} \\
(0.07379)\end{array}$ & - & $\begin{array}{l}1.02161^{* *} \\
(0.06940)\end{array}$ & - & $\begin{array}{l}1.11451^{* *} \\
(0.10900)\end{array}$ & - & $\begin{array}{l}0.96094^{* *} \\
(0.04480) \\
\end{array}$ \\
\hline Median & $\begin{array}{c}87.0548 \\
(7.26496)\end{array}$ & $\begin{array}{l}83.17178 \\
(8.40467)\end{array}$ & $\begin{array}{l}63.84026 \\
(5.79525) \\
\end{array}$ & $\begin{array}{r}64.85024 \\
(6.45466)\end{array}$ & $\begin{array}{l}41.04232 \\
(5.77607)\end{array}$ & $\begin{array}{r}44.09414 \\
(5.84406) \\
\end{array}$ & $\begin{array}{l}69.42941 \\
(3.66033)\end{array}$ & $\begin{array}{r}67.32348 \\
(4.43627) \\
\end{array}$ \\
\hline Log-L & -201.8873 & -201.5101 & -172.2220 & -172.1786 & -79.41737 & -78.89403 & -463.2331 & -462.8276 \\
\hline$N$ & 130 & 130 & 117 & 117 & 57 & 57 & 304 & 304 \\
\hline $\begin{array}{l}\text { Tahmin edilen } \\
\text { ortalama grev } \\
\text { süresi }\end{array}$ & 125.6281 & - & 92.0810 & - & 59.2066 & - & 100.2004 & - \\
\hline
\end{tabular}

- 1-100 işçinin katıldığı grevler küçük grevler 101-500 iş̧̧inin katıldığ grevler orta grevler ve 501 den fazla işçinin katıldıği grevler büyük grevler olarak tanımlanmıştır.

- Parantez içindeki değerler tahmin edicilerin asimtotik standart hatalarıdır.

- \% 1 anlamlılık düzeyinde istatistiksel olarak anlamdır.

- ** 5 düzeyinde birden farkı değildir.

- Weibull model istatistiksel olarak anlamlı olmadığından ortalama grev süresi hesaplanmamıştır. 


\section{Sonuç}

Yapılan bu çalı̧̧ma sonucunda grev süresi ile katılan işçiler arasında negatif bir ilişkinin var olduğu greve katılan iş̧̧ sayısının artmasının grev süresini kısaltacağı sonucuna varılmıştır. Katılan işçi sayısına göre küçük, orta ve büyük çaplı olarak ayrım yapılması sonucunda bu gruplardaki grevlerin birbirlerinden farklı bir süre yapısına sahip olduğu tespit edilmiştir. 1986-1991 dönemi grevlerinin uzunluklarına en uygun düşen fonksiyonun üstel fonksiyon olduğu sonucuna varılmıştır. Bu sonuç beklentilere uygun gözükmemektedir. Grevin zaman geçtikte sona erme olasilığın ifade eden hazard oranınun ampirik hazard oranında olduğu gibi düşmesi beklenmişse de veriler bizi böyle bir sonuca götürmemiştir. Bunun bir nedeni iş̧̧ilerin taleplerinin karşlanmaması durumunda kaybedecekleri ya da kaybettikleri pek fazla bir şeyin bulunmadığ düşüncesi olabilir. Bir başka nedeni ise beklemekten elde edecekleri kazancın beklemeye değer derecede yüksek olmasıdır ${ }^{12}$. Bu çalışma sonucunda sendikalar için oluşan politika, amaca ulaşmak için grev kararın mümkün olan en fazla katılımla almak ve herkesin greve katılımını sağlamak olacaktır. Işverenler için düşünebilecek politika ise mümkün olan en kısa zamanda grevi sona erdirmektir. Çünkü geçen zamanla birlikte grevin sona ereceğine dair herhangi bir ipucu görülmemektedir. Arabulucu konumunda olanlar içinse her iki tarafı mümkün olan en kısa sürede ikna ederek grevin bir an önce sona ermesini ve etkilerini asgari düzeye indirmek bir politika olarak önerilebilir.

\section{Kaynakça}

ASHENFELTER. Orley / JOHNSON, George (1969), "Barganing Theory, Trade Unions, and Industrial Strike Activity," American Economic Review, 59:410.415.

COX, D.R. / OAKES, D. (1984), Analysis of Survival Data (Chapman E Hall).

FISHER, Timothy C. (2001), "An Asymmetric Information Model for Lockouts," Bulletin of Economic Research, 53/2:153.59.

FLORENS, Jean /PIERRE, Denis Fougère / MOUCHART, Michel (1996), "Duration Models," MÁTYÁS. László/ SEVESTRE, Patrick (Eds.) The Econometrics of panel data: A handbook of the theory with applications (Boston: Kluwer, $2^{\text {nd }}$ edition).

GREENE, William H. (1997), Econometric Analysis (Prentice-Hall: International Edition, Third Edition).

HAYES, B. (1984). "Unions and Strikes with Asymmetric Information," Journal of Labor Economics, 2:57-83.

HECKMAN, J.J./ SINGER, B. (1980), "A method for minimizing the impact of the distributional assumptions in econometric models for duration data," Econometrica, 53/2: 271-320.

KALBFLEISCH, J. D / PRENTICE, Ross L. (1980), The Stalistical Analysis of Failure Time Data (John Wiley $\varepsilon$ Sons, Inc.).

12 Bu noktayı dikkate sunan hakeme teşekkür ederim. 
KENNEDY, Peter (1998), A Guide to Econometric (Cambridge, Massachusetts: The MIT Press, Fourth Edition).

KIEFER, Nicholas M. (1988), "Economic Duration Data and Hazard Functions," bumal of Economic Literature, 646- 679.

LANCASTER. T. (1972). "A stochastic model for the duration of a strike," Joumal of the Royal Statistical Society Series A (General) 135/2.

LANCASTER. T. (1990), The Econometric Analysis of Transition Data (Cambridge: Cambridge University Press).

REDER, Melvin / NEUMAN, George (1980), "Conflict and Contract: The Case of Strikes," Joumal of Political Economy, 88: 867-886.

Toplu I\$ Sözleşmesi, Grev ve Lokavt Kanunu, Kanun No: 2822, Yayımladığı tarih: 07/05/1983, www.yargitay.gov.tr.

'86 Petrol Iş. Türkiye Petrol Kimya ve Lastik Iş̧̧ileri Sendikası, yayın no: 13.

'87 Petrol Iş. Türkiye Petrol Kimya ve Lastik Iş̧̧ileri Sendikası, yayın no : 19.

'88 Petrol Iş. Türkiye Petrol Kimya ve Lastik Iş̧̧llerl Sendikası, yayın no : 23.

'89 Petrol Iş, Türkiye Petrol Kimya ve Lastik Işçilerı Sendikasi, yayın no : 25.

'90 Petrol Iş, Türkiye Petrol Kimya ve Lastik Işçilerı Sendikası, yayın no : 26.

'93 94 Petrol Iş, Tūrkiye Petrol Kimya ve Lastik Iş̧̧ileri Sendikası, yayın no : 36.

\section{EK}

Ek Tablo 1. Log duration değişkeninin log iş̧̧ sayısı üzerine regresyonu

\begin{tabular}{|l|l|c|c|}
\hline Değişken & Katsayı & Standard Hata & t-oranı \\
\hline Sabit & 4.5730 & 0.24254 & 18.855 \\
\hline LOGWR & -0.13166 & 0.04690 & -2.807 \\
\hline R-squared $=0.02543 \quad$ p değer $=0.00532 \quad \mathrm{~N}=304$
\end{tabular}

Tablo 2. Grevlerin homojenlik test

\begin{tabular}{|lc|}
\hline Log-Rank $(\mathrm{LM})=17.070$ & Prob. 0.00020 \\
\hline Gen. Wilcoxon $=9.3555$ & Prob. 0.00930 \\
\hline Degrees of freedom 2 & \\
\hline
\end{tabular}


Ek Tablo 1. Log duration değišseninin log isçi sayısı üzerine regresyonu

\begin{tabular}{|llll|}
\hline & & & \\
Degissken & Katsayı & Standard Hata & t-oranı \\
\hline Sabit & 4.5730 & 0.24254 & 18.855 \\
\hline LOGWR & -0.13166 & 0.04690 & -2.807 \\
\hline
\end{tabular}

R-squared $=0.02543 \quad$ p değeri $=0.00532 \quad \mathrm{~N}=304$

Tablo 2. Grevlerin homojenlik testi

\begin{tabular}{|ll|}
\hline Log-Rank (LM) $=17.070$ & Prob. 0.00020 \\
\hline Gen. Wilcoxon $=9.3555$ & Prob. 0.00930 \\
\hline Degrees of freedom 2 & \\
\hline
\end{tabular}

Gafik 1 Weibull hazard oran
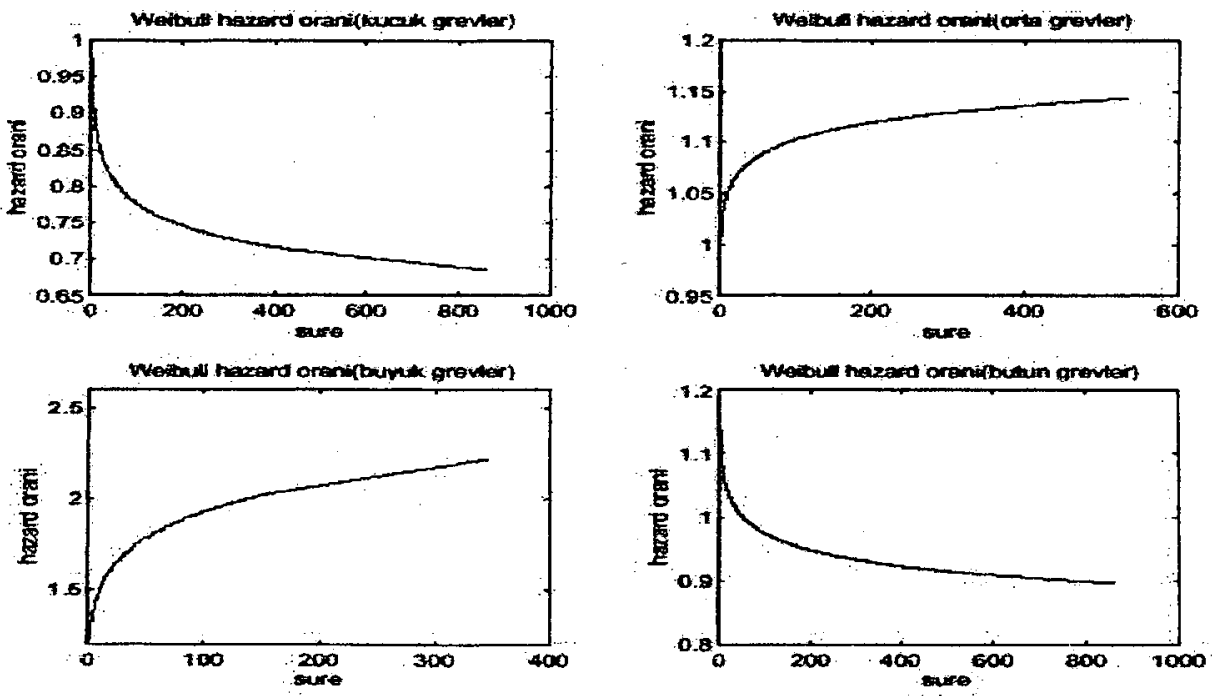
Grafik 2 Ūstel ve Weibull fonksiyoniannın integrated hazard fonksiyonlan
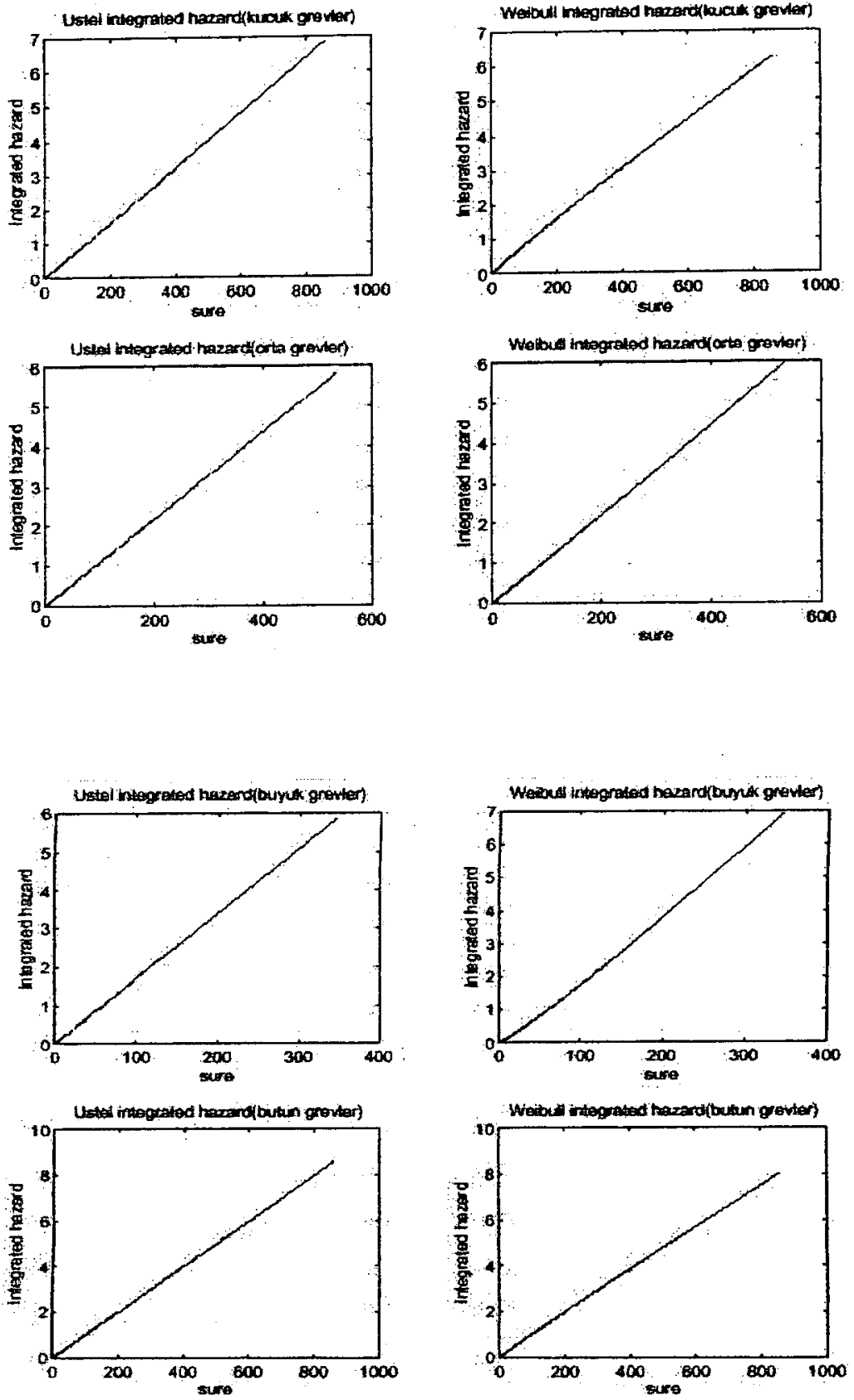